\title{
WEB JOURNALS AND EDUCATION
}

\author{
by \\ Vivienne Monty
}

\begin{abstract}
The Joumal is the most accepted vehicle for the dissemenation of work results and today electronic journals are very much part of that form of dissemination. Electronic Journals (E-journals) come in many forms from academic ones to zines, which are popular and irreverent for the most part. There are many e-journals on the Internet and the Web in education. It is an ideal medium for them. In particular, e-journals in education help the cognitive learning process. The do so by complying with learning series as outlined by Piaget, Kolb, Witkins and others. Through their flexibility with hyperlinks and the varying formats they allow, e-journals can relate to the varying leaning styles of students. Despite of all their positive aspects, there are still a number of issues of concem with this medium of publication such as copyright, stability of format, archiving, updating, indexing and the like. Nonetheless, e-journals will continue to grow and expand due to ease of access and because, in the field of education they promote an interactive learning tool.
\end{abstract}

\section{A Brief History of Journals and E-Journals}

The accepted vehicle for the dissemination of work results or current events is the joumal. It has been a tool of intellectual exchange for centuries, almost as old as print itself.

It is well to remember that the ancestor of today's fancy scholarly journal was the diary or logbook (the original "joumal") in which the scholar or scientist recorded data, thoughts, ideas, meetings, and conversations, much as do today's networked electronic lists. ${ }^{1}$

Just as the New World was being settled, two journals similar to those we have today were being published, the Journal des Scavans and Philosophical Transactions. ${ }^{2}$ Today there are thousands of journals/magazines of all types with new ones appearing daily.

The printed journal has played a central and essential role in communication. In most scholarly disciplines, the accumulated contents of some set of respected journals provides a canonical corpus defining the effective state of knowledge in the field. Electronic media now compete with printing for the communication of texts. Extrapolating from the success of journals that are currently published electronically, it is clear that electronic media will capture a large share of scholarly publication in the next five years, and that printed media will not be competitive in joumal publication beyond a very few more decades. ${ }^{3}$
We have moved from the paper journal to todays e- and hjournal [electronic journal and hypermedia journal]. The first ejournal appeared in 1976 from the New Jersey Institute of Technology. It was the prototype of the e-joumal and was a weekly read-only newsletter. Numerous other ones followed such as, Psycholoquy by 1989, E-Journal by 1991 and the Online Journal of Current Critical Trials by $1992 .{ }^{4}$ A Web search of any major search engine uncovers hundreds of them today in all shapes and sizes. [Major search engines are those such as Alta Vista URL:>http://www.altavista.com or a subject list such as Yahoo http://www.yahoo.com]

\section{The Definition of E-Journal and H-Journal}

What then is the definition or definitions of the e-journal? The definition normally used for an e-journal is a journal available only in electronic format and distributed over the Internet usually without charge as opposed to the online journal which maintains an electronic existence parallel to a print counterpart and tends to be commercially produced. 5 The concepts of online and Intemet have essentially begun to merge with the WEB.

Current evolutionary trends of the e-journal are at what Anita Sundaram refers to as the h-journal. The h-journal:

breaks away from the print journal model of document organization, while attempting to retain most of its functionality and adding its own. It utilizes hypertext and 
the capabilities of the electronic medium to deliver a hyper document that supports differing reading behaviors and users and information can be retrieved by both browsing and known item searching. It includes other document formats (graphics, audio and video) besides text; supports different type of user interactivity such as the ability to interact with the author/publisher/relevant newsgroup; facilitates exploration of dynamic concepts with interaction that is beyond mere descriptive text, through the provision of interactive graphics; extends the information use activity to its fullest potential by utilizing a taxonomy of links to identify relevant documents outside the immediate context; and makes provisions for other forms of data manipulation besides information retrieval, for example, statistical analysis, decision, instruction and editorial kinds of support. ${ }^{6}$

The zine is yet another form of e-journal that in print used to be referred to as the underground press. Today, these are very much above ground but accessible to all. John Labovitz, who has one of the largest zine lists on the WEB, defines zines as being: generally produced by one person or a small group of people, done often for fun or personal reasons, and tend to be irreverent, bizarre, and/or esoteric. Zines are not 'mainstream' publications-- they generally do not contain advertisements, are not targeted towards a mass audience, and are generally not produced to make a profit.?

E-journals today come in varieties that print can barely match. Some are still electronic versions of paper journals, while others use all or part of the power of hyper-media to create living and virtual/interactive articles. These latter ones are called $h$-joumals. Eand h-journals (electronic and hypermedia -joumals) thus operate in an environment that is not possible to capture in paper. The creation of e-joumals is an ongoing process rather than a series of discrete separate activities. Namely, it is a continuous process rather than single separate tasks such as editing, copy conversion and so on. It is this process that makes them unique and distinguishes them from print. ${ }^{8}$ Some e-joumals are scholarly, others are free, some are obtainable on subscription, others are available from trade publishers, and some are pay per view. Many are refereed journals. 9

\section{Journals, the Internet and Education}

The Internet offers numerous opportunities for students and teachers alike to leam and teach in new ways. Information can be exchanged by means never thought of heretofore and it is simple and inexpensive to publish on the WEB. Students and teachers can share their work worldwide. The Internet is extremely well suited for journal type literature and as a means of communications. Hypermedia, it has been argued, is an instructional tool that addresses individual differences in learning styles very well.10 The number of journals in education and related fields that are accessible on the Internet through various sources is getting larger by the day [see list of selected education e-journals in Appendix A].
The field of education was one of the first entrants into the electronic world. ERIC, ${ }^{11}$ which covers many subjects beyond education, was one of the first online databases that was relatively cheap and widely accessible. With the arrival of Gopher and then the WEB on the Internet, ERIC again, because it could be made so freely available, became one of the first indexes that could be searched and its information retrieved.

The concept of electronic journals (e-joumals) in any field seemed like a revolutionary idea just a few years ago. Even in 1990 , the fact that the entire traditional publishing cycle could be accomplished electronically was considered novel and experimental at best. ${ }^{12}$ In the last year, however, many have begun to refer to the WEB itself as a large electronic magazine showing how far thinking has changed about this medium. The Intemet and the Web have become a scholarly vehicle of exchange as well as a trade commons for the commercial sector. This lightning speed in evolution can be attributed to several forces at work simultaneously. The Web has opened the ease of access to the Internet beyond the few to increasingly the many. At the same time, paper prices have skyrocketed to levels that are becoming unaffordable for libraries and other purchasers. In addition to high costs, there are long publication delays and failures of peer review in the scholarly area at least. It has also become, to some degree, less profitable for trade publishers to produce journals in paper. Many have recently created WEB homepages and offer access either to their journal table of contents for free or on a subscription service basis. [See for example http://www.elsevier.com/. Chose TOC or Table of Contents Service]. These considerations, in addition to the flexibility of formats, have taken Web publishing, particularly e-journals, beyond the realm of the esoteric and "truly revolutionary" 13 to the commonplace. The fact that multimedia can be so easily fused into any article on the WEB makes it an ideal medium for education. The ability to merge multi-media is one of the greatest attractions of Web joumals.

Stevan Hamad in the Post Gutenberg Galaxy has given another reason for this rapid growth and popularity. That reason is speed, something to which we have become accustomed in research, publishing and news.

The written medium is hopelessly out of synch with the thinking mechanism and the organic potential it would have for rapid interaction if only there were a medium that could support the requisite rounds of feedback, in 'tempo giusto.' 14

\section{The Internet and Learning Theory}

Education and training are about presenting information and transforming it into knowledge.

By enabling students to link data, information and ideas, interactive multimedia helps to make the connections which are critical to leaming. By integrating text, graphics, sound, animation and video, it addresses different leaming styles, providing a truly interactive leaming environment that students can explore, add to and compose in, enabling them to become actively engaged in the leaming process. ${ }^{15}$ 
It is no small wonder that the field of education has embraced the Internet and its capabilities. The very nature of education is to impartknowledge to as many as possible in the most effective way. Traditionally such work was done for small groups of students and occasionally for tutoring of individuals. The WEB, however, provides a gateway for using all sorts of media and to project these to large and varied audiences. No longer need a teacher just prepare a lesson plan or lecture for a small group, today such leaming can be shared and interchanged amongst colleagues in "real time."

In an analysis, history and survey of leaming styles, Ayersman outlines how computers help in learning by making leaming more interesting. He bases his arguments for this on the prior work of Piaget, Kolb, Witkin and others, pointing out how cognitive learning is enhanced by the use of hypermedia environments. There is a tremendous importance in the experience of learning provided by and through the use of hypermedia. ${ }^{16}$

Another reason e-joumals have been embraced is the speed and ease with which publishing can occur. "Any developments in the area of electronic data transfer that can be called to maximise the efficient use of time are going to be of utmost importance."17

E-joumals provide, most of all, a level of flexibility that has made them a huge success. Articles can easily be downloaded, and manipulated for future use. Access to them is at anytime of the day or night and they are often findable more easily, unlike paper joumals in a library or even at home. Ejournals also provide instant feedback and exchanges with colleagues through WEB interconnectivity.

The field of education fits hypermedia in particular because it combines a multiplicity of fields for the purpose of imparting knowledge. Perhaps the greatest breakthrough for the e-journal has been the ability to attract readers in many fields. In surfing through the Net, many find sources that ordinary shelf browsing would never have lead them to. Several authors have mentioned this in the literature on e-joumals. One e-joumal, the Joumal of ComputerMediated Communication, actually states in its statement of purpose, "The computer as a medium fosters new forms and supports established modes of social interaction... Such work has been scattered over half a dozen disciplines with no home of its own."18

Links on the WEB allow most easily for inter- and intradisciplinary connections to be drawn together. A teacher, for example, might be interested in educational theory as well as in communications through technology and a specific subject field all at the same time. This multidisciplinary type access and breakdown is the very "democratic" nature of the WEB/Internet which allows the field of education to see its true reflection. Many who have constructed homepages, whether in education or other fields, provide links within their pages to other sites of relevant and or related data. The Web makes access to such related links seamless to users. They derive information by clicking on links but if the information is pertinent there is no need to ask what discipline it is from. It does not matter as long as the relevant information is obtained.

\section{E-Journal Formats}

For the most part, e-joumals emulate their paper cousins. Differences might be few such as the reader might have to click several times before reading a complete article, there might be some prettier pictures and there are occasional hot links in the text though this is still relatively rare. ${ }^{1}$ This traditional use of the Internet is not a criticism, just a mere fact as this format of joumal publishing is still very much in the growth and changing state. Many editors are in the process of leaming the techniques of html [hypertext markup language] and similar WEB publishing software. The new venue despite its lack of novel uses of features in this new media nonetheless makes effective use of the speed and oneness of the Intemet. Psycholoquy, [URL:>http://www.cogsci.soton.ac.uk/ psycoloquy] Stevan Harnad's Intemet joumal was, in 1990, one of the first to include hypertext threads and online peer commentary which is becoming more commonplace. Only those e-joumals that have no paper counterpart can undertake such advances since paper cannot interlink. 19

The h-joumal, the newest entry, has introduced links to all types of media within an article. This is probably the route the field of education will take. It is ideal to incorporate video interviews or graphics or the 'real thing' into an article. McLuhan's "the medium is the message" certainly is made truer by h-joumals. H-joumals get away from mere text and interrelate all types of media (voice, video, graphics etc.) into a single work. Furthermore, such media are often not integrated locally into the article but are linked by hyperlinks from other sites. ${ }^{20}$ In constructing an h-joumal article, a writer can link various other data/articles/media etc. to their paper from other sites through links and they become an integral part of their work. Such links in traditional print could only be created by footnotes which then readers had to find on their own but could not reach instantaneously. With hyperlinks, writers can better relate a topic in whatever media they think might impart the concept best. They can also provide multiple type media if they are trying to reach readers who have different leaming styles. The experimentation with such articles is in its infancy. ${ }^{2}$ Embedding of hotlinks within an article can have grave consequences for creator integritiy. While such articles make effective and proper use of the Web, what if these critical links

1. A hot link is an altemative term for a computer direct link which provides access to further data within one site or data at other remote site(s) through clicking on the highlighted text. The ability to move with these links from information bits to information bits and throughout the world is seamless.

2. It should be noted that remote links to other media, not controlled by the authors or created by them, brings about questions of copyright, availability of the link and such similar questions which are fraught with danger because there is no guarantee that such works will last over time as an integral whole and which has been incorporated on an article by an author. 
are lost?23 On the other hand, copying the data for local use and keeping it online is not very efficient use of the technology. Also, if articles are imported and copied directly into someone else's work, rather than by mere linking to the work, copyright implications could become quite chaotic.

\section{E-Journals and the Role of the Librarian}

The librarian can and does play a key role in the realm of ejoumals as well as other forms of WEB documentation. "By using the networks themselves, librarians can prepare to serve as guides to the emerging infrastructure of machine-readable information just as they do for printed materials." 22 These roles, it could be stated, date back to libraries as trustees for society in preserving, organizing and providing access to the networked information environment. ${ }^{23}$ In a further expanded view, if libraries do assume the role of publishers or electronic editors, they would be accountable for the correctness, reliability and the quality of the work. 24

Librarians can add to their roles extending their traditional roles to the new e-culture. Already librarians are providing training and promotional activities in association with electronic materials. Furthermore, they could be identifying users' needs to publishers and e-journal providers. ${ }^{25}$ Indeed, it has been argued that when large quantities of articles are published as e-journals each year as opposed to just a few articles as in paper publishing, the library with its professional staff of librarians is the only institution which has the expertise to organize, input, format and distribute such a volume. Libranans have been doing this for decades by managing large university libraries of millions of volumes. ${ }^{26}$

Librarians have already undertaken cataloguing projects to identify e-journal titles. OCLC has a contract to catalogue Internet titles including e-joumals. 27 The National Library of Canada is currently in the midst of a study for the control, access, cataloguing and mirroring of e-journals. ${ }^{28}\left({ }^{3}\right)$ Other projects have been mentioned earlier. Many libraries are cataloguing ejoumal titles with hot links for their new Web catalogues. ${ }^{29}$ Hotlinks embedded in articles allow for an increasingly expanded range of subject knowledge and connections to other fields and type of data by the click of a finger.

Educators and librarians have a critical role to play in the area of standards. Quinn makes a strong case to "move forward a few steps in the quality-control chain." from our past role as simply applying more standards than simply deciding whether to buy or not buy a joumal. 30

\section{E-Journal Issues and Concerns}

The issues mentioned below come up continually in conversations dealing with e-joumals. Many of them are also mentioned in most major articles dealing with e-journals in any way. What then are some of these issues:

Archiving is a critical issue conceming e-joumals that has had as much discussion as any other issue. Solutions seem to be illusive for the moment. One of the largest problems is the changing nature of the technology to create, browse and store e-journals for posterity. In one way, digitized documents may be distributed more widely because of the ease of downloading and replication. On the other hand, they are, by the same token, far easier to destroy.

Another concem is that newer versions, with their graphics, video, audio and extensive use of hotlinks do not lend themselves very effectively to ASCII format. Such technological problems will have to be addressed and soon solved if we are to have any record for the future of e-materials in the future.

Copyright is another area that seems beyond immediate solutions. The republication of e-journal articles in full text have "upset the traditional relationship between authors, publishers and librarians." 31 This issue could become the most divisive of all issues concerning e-journals as lines are very much divided. Legislators do not even wish to touch this issue for the most part. The electronic miracle has made copyright infringement quite easy. Simply get, download and manipulate anything on the Internet and it is ready for republishing. Students have been doing this foryears with abstracts to indexes online. They merely download the abstracts, string them together as text and a finished paper is thus produced. Digitization makes this very simple, much more so than retyping was. Some argue that such easy infringement might be part of the undoing of this brave new world for if the creator has no recognition of their labor, they will simply have no incentive to share or create. On the other hand, the very same issues were brought up when print was first invented and then when photocopiers came on the market. The problems have increased. On the other hand, it is possible to argue that widespread dissemination provides more eyes and memories to catch someone infringing copyright. ${ }^{32}$

Some e-journals, produced by not-for-profit groups or individuals, allow the creator of e-journal articles to retain copyright of their own work. The trade press and scholarly publishers, both for profit, demand that copyright be signed over to them for electronic formats as well. In the trade press, one answer might be that there will be more staff writers writing actual articles for journal issues. Such writers do not have copyright on their work but their publishers do.

3. Mirroring is the practice of a site(s) carrying the same data as the originator of information, i.e. mirroring a site, so that the information at the original site can be made more widely and more quickly accessible. It is essentially the Internet version of multiple copies of works throughout different resource centers. ${ }^{32}$ 
Updating online information is extremely easy as opposed to the difficulty of updating paper publications. The question thus arises as to whether once an item has been published whether the author and/or publisher are committed to updating the information in the article. If the decision is made to update it, then should the various versions all be available online? Outdated information and various versions have had great uses in the past that reflect change in thinking and evolution of thought on a topic and so on. In the future, some authors might not want to continue to make outdated information available for fear that this would reflect negatively on the author's expertise. Thus, should an article be withdrawn at the creator's request? If so, what of archiving original issues for the future?

In yet another scenario, if updating becomes commonplace almost mandatory, will authors be forced to constantly update an original piece? Such work could become onerous in the least and boring to many authors as well. Also, authors often move onto other subjects of interest and do not necessarily want to maintain full knowledge in the subject matter on which they published years earlier. If updates are done by someone else or a publisher on the otherhand, will the original creator(s) get credit?

Another matter yet to be addressed is citation beyond the URL's [Uniform Resource Locator or Internet address] currently given. They also tend to be unstable. Segmentation of articles is another concern. Some articles are far too large to be effectively loaded as a single document. These are often segmented for ease of use. Retrieving a single article might take several downloads as a result which can be most time consuming.

One other major issue that has yet to be dealt with is what constitutes a subscription in the e-journal world. Subscriptions in the present environment are to current issues. When the subscriber ceases to subscribe, will they still have access to the years they have subscribed to or will all access cease? Almost certainly they will have access while subscribing currently only. The subscriber in the paper world still had access to all the back issues they had paid for. Future e-joumal subscriptions might well be payment for access only but not to have materials in kind. Subscriptions in the future might well have to be negotiated contracts for a 'download and keep' agreement with publishers.

\section{Subject Fields in the E-Journal World}

Some subject fields are better represented in the e-journal world than others. The reasons for this vary widely. Mathematics has generated a very large number of online joumals. ${ }^{33}$ Physics, medicine and biology are not far behind. All of these fields have had for sometime a preprint culture that has made them ripe for ejournals. These fields of study were also amongst the first to use computers extensively. Also, formatting such as Postscript and the mathematical language of $\mathrm{TeX}$ and Adobe Acrobat allow for printing the specialized nature of these subjects.

Not surprisingly, two fields that are almost as well represented in the last few years are education and the arts, but for very different reasons. ${ }^{34}$ Education has digitized a large number of journals for some years and made them accessible at very low costs and sometimes for free, especially those subsidized by the USDE (United States Department of Education). These e-journals such as Educom URL:>http:// www.educom.edu or TH.E Journal (Technological Horizons in Education URL:>http://www.the journal.com) ${ }^{35}$ are readily available. Education, as well, by its very nature as a subject, is committed to teaching and learning. This field has made extensive use of the Intemet for classroom instruction of all sorts.

There are tremendous resources out on the Web for selfleaming and professional development. Since $70-80 \%$ of adult learning is self-directed, this is a incredible advantage. T.H.E. Journal (Technological Horizons in Education) stated that with global information available, teachers will be able to share best practices with other teachers and "have the opportunity to stand on the shoulders of other people's outstanding work."36

E-journals are popular in the Arts primarily because this medium provides the ideal venue for presentation of materials. Hypermedia allows graphics and other media, central and key to the artist's work to be presented just as the artist has designed it. The Internet provides the creative tool which people in the arts use every day. In fact, some of the most interesting e-journal experimentation has taken place in the field of arts. For example, the Website the BodyMissing [URL:> http://www.yorku.ca/ BodyMissing] is a joumalistic type tour of art that was stolen and found again after the second world war. It explores the policy of the Nari 'kinstraub'. The visitor enters a gallery or 'transit bar' and then choses on which path to continue by clicking on various objects. Visitors enter various versions of the bar and then move between tales of the missing art from different aspects. There is sound, video, manuscript, graphic, and other media to chose from at each level.

\section{Conclusion}

E-journals are a complex matter about which there has already been much discussion and considerable more evolution in the last few years. The next decade will see a great deal more. As with anything new and emerging, further discussion needs to take place. Many issues conceming e-journals, however, are already being addressed by various projects such as the National Library of Canada Journals Project [URL:>www.nlc-bnc.ca] and Project Muse at Johns Hopkins [URL:> http://muse.jhu.edu] and those mentioned in references above. E-journals will represent a new form of publishing that is truly revolutionary if we continue to use the new technologies effectively.

The Internet offers the field of education a method by which interactive learning as well as different styles of learning may be used to achieve the maximum in teaching and leaming. It also offers school librarians a wonderful opportunity to integrate and demonstrate some of the skills that they already had but many were unaware of, such as their knowledge of the structure of datafiles and modes of boolean searching for effective results. Moreover, the new journal could create an interactive leaming tool/lesson as has never seen before. 


\section{Appendix A: Selected List of Education E-Journals on the WEB}

Most of the following are free and a few are on subscription.

Catalyst [http://borg.lib.vt.edu:80/ejournals/CATALYST/catalyst.html]

Chreods [http://s13a.math.aca.mmu.ac.uk/Chreods/Chreods_Intro.html]

CyberSchool Magazine [www.infoshare.ca/csm/index.htm]

Education Policy and Analysis Archives [http://olam.ed.asu.edu/epaa]

Education, Research and Perspectives [gopher://gopher.ecel. uwa.edu.au:70/ 11/archives/education/erp]

Education Week on the Web [http://www.edweek.org]

EduCenter Journal [http://www.talkcity.com]

Educom Review [http://educom.edu/web/pubs/pubHomeFrame.html]

Edupage [http://educom.edu/web/pubs/pubHomeFrame.html] Chose Edupage

Interactive Teacher Online [http://mww.mlab.com/itoreg]

Interpersonal Computing and Technology: An Electronic Journal of the 21st Century [http://mww.helsinki.fi/science/optek]

International Journal of Continuing Education Practice [Send email to CONTED@max.cc.uregina.ca]

Journal of Extension [gopher://joe.org/11/joe]

Journal of Higher Education [gopher://gopher.acs.ohio-state.edu:70/11/ Journals\%20\%26\%20Newsletters/OSU\%20 Libraries]

Journal of Technology Education [http://borg.lib.vt.edu/ejournals/jte/jte.html]

New Horizons in Adult Education [gopher://gopher.acs.ohio-state.edu:70/ 11/Journals\%20\%26\%20Newsletters/OSU\%20Libraries]

Online Chronicle of Distance Education and Communication [gopher:// gopher.acs.ohio-state.edu:70:11/Journals\%20\%26\%20Newsletters/ OSU\%20Libraries]

Teacher Magazine [http://www.edweek.org/tm/tm.htm]

Teacher Talk [http://education.indiana.edu/cas/tt/tthmpg.html]

TESL-EJ [http://violet.berkeley.edu/ cwp/TESL-EJ/index.html] 


\section{Endnotes}

1. Anne Okerson, "Electronic Joumal: What, Whence and When?" PACS - Review 2, no. 1 (1991): 17

2. C.B. Osbum, "The Place of the Joumal in the Scholarly Communications System," Library Resources and Technical Services 28, (1984):315-324.

3. M.J. O'Donnell, Electronic Journals: Scholarly Invariants in Changing Medium (Snowmass, Colorado: Seminars on Academic Computing 1993 University Executive Program) [URL:http://www.cs.uchicago.edu/users/odonnell/OData/ Technical_Papers/Electronic_Joumals/description.html].

4. Stephen Harter and Hak Joon Kim, Electronic Journals and Scholarly Communication: A Citation and Reference Study, (A Paper delivered at the Midyear Meeting of the American Society for Information Science, San Diego, 1996) [URL:>http:/ /ezinfo.ucs.indiana.edu/ harter/harter-asis96midyear.html].

5. Linda Langscheid, "Electronic Joumal Forum: Column 1," Serials Review 18:1-2 (1992):131.

6. Anita Sundaram, Towards the Design of an Hypermedia Journal (Urbana: University of Illinois 1990) [URL:http:// alexia.lis.uiuc.edu/ sundaram/phd].

7. John Labovitz, E-ZINE LIST, [URL:http:// www.meer.net/ johnl/e-zine-list].

8. H. Julene Butler, "Abstracts of Papers Presented at the International Conference on Refereed Joumals, October 1993," Serials Review 20: 4 (Winter 1994):27

9. Butler, p23.

10. David Ayersman, "Individual Differences, Computers, and Instruction," Computers in Human Behavior 11:3-4 (1995):371-390.

11. Liselle Drake and Lawrence Rudner, Internet Resources for Guidance Personnel. [ERIC Digest no. 391988] 4p.

12. David Pullinger and Brian Schakel, BLND-3: The Electronic Journal Research. Technical Report Paper 79. (London: British Library Research and Development Department, 1990).

13. Stevan Hamad, Post-Gutenberg Galaxy: The Fourth Revolution in the Means of Production of Knowledge, PACS Review 2, no. 1 (1991):39-53.

14. Hamad, p. 7.

15. John Barker and Richard N. Tucker, The Interactive Learning Revolution, London: Kogan Page, (1990)

16. David Ayersman, An Overview of the Research on Leaming Styles and Hypermedia Environments: Paper Presented at the Annual Convention of the Eastem Educational Research Association. Clearwater, Florida [ED356756] (1993):18pp.

17. Knista Jenkins, Scholarly Publishing and Electronic Journals (University of South Australia, School of Library and Information Management) [URL:http://infotrain.magil. unisa.edu.au/Infotrain/ VolumeOne/InfoMan3/JenkinsKrista/Ejoumal.htm].

18. Journal of Computer-Mediated Communication: announcement (June, 1994) [URL:http://www.huji. ac.il/ www_jcmc/jcmc.html]

19. Steve Hitchcock, Leslie Carr and Wendy Hall, A survey of STM Online Journals 1990-95:The Calm Before the Storm, (University of Southampton, Multimedia Research Group) [URL:http://joumals.ecs.soton.ac.uk/survey/survey.html].
20. Robert Cameron, To Link or To Copy? Four Principles for Materials Acquistion in Intemet Electronic Libraries, Simon Fraser University, School of Computing Science (1994) [URL:http://fas.sfu.ca/projects/Electronic Library/project/ papers/e-lib-links.html].

21. Ibid.

22. Caroline Arms, "Using the National Networks: Bitnet and the Internet," Online (September, 1990):24.

23. Clifford Lynch, "Rethinking the Integrity of the Scholarly Record in the Networked Information Age," Educom Review 29: 2 (March/April, 1994)

24. Susan Rathie, Electronic Joumals and Peer Review: Perils and Promises (Vancouver: University of British Columbia, Faculty of Commerce and Business Administration -MIS Division) [URL:http://www.es.ubc.ca/spider/rathie/lecpub/paper3.html].

25. Value Librarians Add to Professional and Scholarly Information (Section Publishing - Joint Working Group) [URL:http://arl.cni.org/clr].

26. Robert Kling, "Controversies about Electronic Joumals and Scholarly Communication: an Introduction," The Information Society 11:4 (1992/93):243-246.

27. Hazel Woodward, and Cliff McKnight, "Electronic Joumals: Issues of Access and Bibliographic Control," Serials Review 21:3. (Summer, 1995):74.

28. National Library of Canada Electronic Collection, [URL:http://www.nlc-bnc/eppp/e-coll-e.htm].

29. Cameron

30. Frank Quinn, "A Role for Libraries in Electronic Publication," Serials Review 21:2 (Spring 1995):28.

31. Deborah Grimes, Copyright and Electronic Joumals, [URL:http://bliss.berkely.edu/impact/copyright.html].

32. Hamad

33. Hans Roes, "Electronic Joumals: A Survey of the Literature and the Net," Journal of Information Networking 2:3 (1994):169-186.

34. Harter and Kim, p. 5-6.

35. T.H.E. Journal (Technical Horizons in Education) [URL:http: //www.thejoumal.com].

36. Bill Gates, "The ConnectedLeaming Community: Using Technology for Education,” TH.E. Journal 3, (1996) [URL:http:/ /www.thejoumal.com].

Vivienne Monty is Senior Librarian at the Leslie Frost Library, York University, Toronto, ON. She is the author of three books on business in Canada and numerous articles in the field of Business and Government Information. Recently she has delivered several papers on the Internet/ Web, particularly concerning electronic journals and web page design. Her CD-ROM Index to the Monetary Times of Canada, 1967-1992, has just been published by reference Press of Canada. 